\title{
Educational Equipoise and the Educational Misconception: Lessons from Bioethics
}

\begin{abstract}
Some advances in bioethics regarding ethical considerations that arise in the context of medical research can also be relevant when thinking about the ethical considerations that arise in the context of SoTL research. In this article, I aim to bring awareness to two potential ethical challenges SoTL researchers might face when playing a dual role of teacher and researcher that are similar to the challenges physicians face in their dual role of physician and researcher. I argue that two commonly discussed concerns in bioethics-the need for clinical equipoise and the possibility of a therapeutic misconception-have analogies when conducting some types of research on students. I call these counterparts educational equipoise and the educational misconception.
\end{abstract}

\section{KEYWORDS}

research ethics, educational equipoise, educational misconception, bioethics

\section{INTRODUCTION}

Some researchers invest a lot of time and effort in designing and implementing scientific experiments that test the of a variety of interventions, and then advocate for using their findings to better design policies in a wide range of areas. It seems only natural to wish to use such expertise in order to guide policies in an area in which these researchers are the sole deciders of the policies: their teaching. Relying on research to determine what teaching methods work in their own policy domain, rather than relying on anecdotal evidence or armchair philosophizing makes a lot of sense. When these researchersteachers engage in Scholarship of Teaching and Learning (SoTL), they are usually very much aware of the need for their research to be both methodologically sound as well as in compliance with academic research ethical standards. There is plenty of discussion in SoTL journals on how to conduct research that succeeds in doing both. However, when looking into work in bioethics, it becomes clear that there are some ethical concerns in SoTL that have not received adequate treatment.

In this article, I argue that two commonly discussed concerns in bioethics - the need for clinical equipoise and the possibility of a therapeutic misconception-have analogous counterparts when conducting some types of research on students. ${ }^{1}$ In particular, I focus on research that employs an experimental design that attempts to emulate a randomized controlled trial (RCT), by using a control group to measure the effects of a particular intervention. RCTs have come to be considered a "gold standard" in clinical trials, and despite some shortcomings have grown in popularity in other disciplines as well. ${ }^{2}$ These counterparts, which I call educational equipoise and the educational misconception, are two potential ethical challenges that SoTL researchers might face when playing the dual role of both teacher and researcher. 


\section{FROM TEACHING TO RESEARCH}

If I were to implement some new pedagogical method in my classroom and did not bother trying to evaluate in any rigorous manner whether it achieved the aims I suspected it does, that would be within the bounds of normal and acceptable teaching practices. I would not be required to check with anyone whether the new method is acceptable, let alone submit my planed implementation to an Institutional Review Board (IRB). Of course, some pedagogical methods are off the table, such as insulting students (even if it were conducive to their learning), but the usual attitude is that oversight is lax, at least in part due to academic freedom. By contrast, I might intend to implement the same method but use standard social scientific experimental methodology to do so. In this case I would no longer simply be participating in the usual practice of teaching but would be delving into the realm of research on human subjects (my students) with all the potential bureaucratic baggage this entails.

This is true even if $I$ have no intention to publish my findings. The intention to publish is sometimes viewed as a critical distinction between "scholarly teaching" and the "Scholarship of Teaching and Learning." Scholarly teaching refers to teachers who "are both intentional and systematic when they institute changes in their courses." But once teachers go through the peer-review process and publish their findings they are engaging in Scholarship of Teaching and Learning (Smith 2008, p. 263). So, even if I have no intention to publish my findings, and I am merely engaging in scholarly teaching, what I am engaging in can be thought of as research on human subjects, with all that it entails. Since there is no intention to publish, others might never find out that I have conducted research on human subjects. Since I do not intend to submit my research to peer review, no one will ask me whether I received IRB approval. Nevertheless, IRB approval is required for both published and unpublished research. As I detail below, the criterion is only whether the research is conducted on human subjects.

It would be odd to think that if 1 act on a whim I face lower ethical standards than I would if I act deliberately and thoughtfully. If I approach teaching in a scholarly fashion, I am subject to guidelines regarding research, whereas if 1 approach teaching without such rigor, I am less restricted. It seems that in either case I am merely trying to figure out how to help my students learn. But the devil is in the details. When conducting a SoTL controlled experiment, I divide my students into two groups, one that receives the treatment and one that acts as a control group. Even if in both cases I intend only to benefit my own students, the intended beneficiaries are two different groups. ${ }^{3}$ If 1 merely implement a new method, I am intending (I hope) to benefit the students in that class. I might decide I like it and continue to use the method, but the initial intended beneficiaries are the students in that particular class. If 1 implement a new method while using a control group in order to rigorously evaluate its effectiveness, I do so in order to benefit some students in that class, but also students in future classes.

Perhaps, though, future students are not relevant as intended beneficiaries (assume I am about to retire next semester). Perhaps I merely use the evaluation in order to assess effectiveness but do so neither to disseminate the knowledge nor for the benefit of future students. It is possible that my intention is only to know whether the intervention was successful. It must be the case that in such a scenario I find some value in the knowledge gained by the evaluation and so am intending to benefit myself in addition to benefiting my current students.

While the unreflective teacher who implements some new method without intention to evaluate its effectiveness might seem too capricious, there is the possibility that his motivation is solely to benefit his current students. It might not always be the case that he is focused solely on them, but it is possible 
that this is the case. The reflective teacher who seeks to evaluate the effectiveness of her new method, on the other hand, must, as a matter of logical necessity, have some additional motivation beyond benefiting her current students. This might be the intention to publish her findings, merely learning for her own interest whether it worked, or benefiting future students.

All this might seem to assume that the methods being evaluated are semester-long methods. These could be a novel course grading policy designed to motivate students differently, or perhaps a sharper focus on course goals to guide my course plan. However, it is possible to implement a short-term intervention, evaluate it, and act on that knowledge to the benefit of the students that are subject to the intervention. For example, I might suspect that singing a song in the beginning of a class might help my students concentrate better and thus better achieve their daily class learning goals. I can implement the method, evaluate it, and act on that knowledge during the next week, thus benefiting the same students on whom the intervention is implemented.

But if use a control group in order to assess effectiveness, even if it is only for one song-less class, the evaluative element means that the students in the control group were subject to one less class of my wonderful (terrible) singing than was possible once I thought of the method. This might be small potatoes in the larger scheme of an entire semester, but the point still holds. Necessary as it might be for evaluative purposes, the control group was not wholly the intended beneficiary of my plan to implement the new teaching method.

\section{FROM ACADEMIC FREEDOM TO INSTITUTIONAL REVIEW BOARDS}

The 1940 Statement of Principles on Academic Freedom and Tenure by the American Association of University Professors and the Association of American Colleges states, among other things, that "teachers are entitled to freedom in the classroom in discussing their subject" (p. 14). The only limitation mentioned is that "they should be careful not to introduce into their teaching controversial matter which has no relation to their subject." A 1970 comment clarifies that what is meant is not that controversial issues should not be taught, but only that teachers should avoid persistently introducing controversial topics that are unrelated to the subject (p. 14). Thus, how teachers go about teaching in the classroom is up to them.

While academic freedom in teaching ought to be respected, when a teacher conducts research on her own teaching, some ethical considerations arise. What are the particular ethical considerations a teacher-researcher ought to consider? Martin (2013) makes clear what requirements IRBs place on such research. Martin begins by making clear that IRBs were not designed with SoTL in mind. On the face of it, SoTL involves research on human subjects and thus is falls under the purview of IRBs. However, what exactly counts as research (e.g., does institutional assessment count?) and what counts as using human subjects (e.g., does using old student exams count?) can sometimes be less than clear. Nevertheless, Martin recommends seeking IRB approval when data on students is collected; if the teacher-researcher is not sure, she can always ask the IRB chairperson for guidance. But while understanding the need for complying with IRB procedures is important, discussing compliance with IRB protocols is not the same as discussing the ethical considerations surrounding SoTL research.

Others have addressed ethical concerns more directly. McKinney (2007), for example, also stresses the importance of submitting one's research protocol to an IRB for approval. Yet she goes beyond merely being concerned with IRB approval, and considers ethical issues that might arise specifically in SoTL. McKinney focuses on three central ethical issues: the importance of informed 
consent, the right to privacy, and protection from harm. First, it is difficult to be certain that there indeed exists true informed consent when there is a power relation between teacher and student. Second, the need to document students' performance for grading purposes and the need to maintain anonymity for research purposes can sometimes conflict. Third, students might be subjected to harm, such as lowered self-esteem as the result of learning that their level of work is much lower than their peers. ${ }^{4}$

Nevertheless, I am addressing an issue, which while many are aware of it to some degree, has not received sufficient attention: the dual role of researcher and teacher that any SoTL researcher plays. Swenson and McCarthy (2012) express a concern for the effects of this dual role and its clinical equivalent when discussing unequal benefits for two groups: "If the experimental group outperforms the control group, then protections must be in place to protect the control group, similar to control group protections in therapeutic intervention research" (p. 28). Similarly, McKinney mentions the ethical concern with the possibility of withholding some potentially beneficial teaching practices from a subset of students when conducting comparative research designs (p. 57). She is particularly cognizant of this problem arising when conducting a controlled experiment:

It is also possible to contribute to the situation where a student learns less or earns a lower grade than he or she might in another situation (social harm). For example, this could occur in a quasiexperiment where one section of a course receives a learning opportunity or pedagogical innovation that the researcher believes (and the study later confirms) enhances student learning, but the other section of the course is not offered this opportunity/innovation. (p.65)

Fenton and Szala-Meneok (2010) state the case even more clearly: "Students enroll in courses for the purpose of gaining knowledge and mastery of a topic rather than to be participants in research projects run by their professors" (p. 24). Lastly, Pritchard (2002) specifically mentions the educational misconception as analogous to the therapeutic misconception that is discussed extensively in bioethics (p. 6). While all these scholars have alluded to what I call the educational misconception in one way or another, in the next section I discuss this educational misconception in much more detail than has previously been done.

\section{FROM THERAPEUTIC MISCONCEPTION TO EDUCATIONAL MISCONCEPTION}

Appelbaum, Roth, and Lidz (1982) coined the term therapeutic misconception in order to describe some research subjects' mistaken belief that decisions about the care they receive during a medical experiment are made solely with their welfare in mind. Testing the prevalence of the therapeutic misconception, Appelbaum et al. found that many subjects, even those in what they took to be an ideal consent process, mistakenly believed that their treatment would be chosen based on what the researchers thought would best benefit the subjects rather than based on what benefited the research. But sometimes the goals of research and the goals of therapy conflict. For example, only some patients receive the actual treatment while others are merely provided a placebo. The decision who gets what is not based on need, but is randomized to insure validity. Similarly, while it might be beneficial for a patient-subject to have her dosage adjusted based on her reaction to the treatment, patients' doses are preset at certain levels to insure validity.

Appelbaum et al. found that many subjects are not even aware that a tension between therapeutic goals and research goals might exist. ${ }^{5}$ Merely explaining the experimental design and key 
terms is not enough to overcome the therapeutic misconception. Researchers would need to directly and explicitly tell subjects that the goals of research and therapy may be in conflict, and that they are prioritizing the former. Yet Appelbaum et al. are skeptical that even such drastic measures would be sufficient, because they think that " $[\mathrm{t}]$ he power of the mind to hear only that which fits its preconceptions cannot be over-estimated" (p.328).

What makes the therapeutic misconception problematic is that potential subjects enter a clinical trial for the wrong reasons. If they believe that the clinical trial is aimed at providing them the best treatment for their situation, the subjects are making cost-benefit calculations based on false assumptions. While it might be in the subjects' self-interest to participate in the trial, they would be overestimating the benefits to them. If there are costs involved, such as risks of side effects, time wasted, or alternative treatments forgone, these subjects fail to adequately weigh them in their decision. If the benefits of participating were actually understood, it might be the case that potential subjects would deem the costs to outweigh the benefits and decide not to participate. Under the therapeutic misconception, patients are less likely to decline to participate.

Why is the therapeutic misconception so prevalent? Dresser (2002) argues that a variety of social forces make it difficult to reduce the misconception. First, the researchers perpetuate the misconception, whether intentionally or not, through informed-consent forms couched in therapeutic language, emphasizing — and perhaps exaggerating — medical benefits to subjects, referring to subjects as patients, and referring to treatments rather than interventions. Second, researchers, who entirely depend on having a sufficient number of subjects in order to continue their research, have little incentive to disillusion their subjects. When it appears to subjects that participating in research is in their self-interest as patients, recruiting subjects is easier. Third, physicians often encourage their patients to participate in medical research as subjects, based on the physicians' own beliefs that participating in the research will benefit their patients. Fourth, in the past few decades, participation in experimental research has been reframed in the public eye as providing access to cutting-edge treatment, rather than the older, more sinister view of medical experiments as harmful — which, again, strengthens the therapeutic misconception. Lastly, popular media that reports more frequently on successful clinical trials than it does on failures, and patient advocacy groups that are intent on generating more research are complicit in generating an inaccurate narrative of the benefits of participating in medical research.

Just like a therapeutic misconception can occur in biomedical research, an educational misconception can happen in SoTL research. Once teachers decide to evaluate an educational method they consider implementing, they introduce an additional goal to their classroom besides getting students to learn as best they can. This research component in the classroom creates two potentially conflicting goals: (1) teaching one's students to the best of one's ability and (2) figuring out which teaching methods help accomplish this. These two goals parallel the dual goals in clinical research: (1) providing the best treatment possible and (2) figuring out what that treatment is. This duality and the lack of awareness of it are what give rise to the therapeutic misconception in medicine. Patients are not aware, do not understand, or ignore the fact that they are participating in a clinical trial that has an additional and perhaps conflicting goal of determining what treatment works best. Instead, patients incorrectly believe that the only goal of their treatment during the clinical trial is to provide them with the best treatment possible. Likewise, students in a classroom in which the teacher is conducting research in order to evaluate what teaching method works best might be under the misconception that 
the only goal of the classroom activities is to provide them with the best education the teacher can offer. Thus, the analogous educational misconception can arise. ${ }^{6}$

While the term therapeutic misconception originally referred to the perspectives of subjects, Miller and Brody (2003) argue that physician-researchers themselves misconstrue their role as researchers and mistakenly believe that they have a therapeutic obligation as well. Miller and Brody argue that this confusion is what gives rise to a mistaken demand for clinical equipoise, the demand that different arms of a clinical trial are acceptable only if there exists a genuine uncertainty in the medical community whether one treatment arm is superior to the other. While Miller and Brody's views are considered controversial among bioethicists, an analogous teachers' educational misconception does sometimes arise, even among the most cognizant SoTL researchers. Gurung and Schwartz (2009), for example, argue that justice requires that those who participate in research should be those who benefit from it the most. According to Gurung, " $\mathrm{t}$ ] his is an area of research ethics in which the Scholarship of Teaching and Learning seems to truly shine” (p. 140). Gurung and Schwartz argue that students who participate in research benefit from the knowledge gained through the study they are participating in. I argue the opposite point. The students Who participate in the research as subjects, or more precisely those in the trial arm that turns out to be worse off (either the test group or the control group), are precisely the group that does not benefit from the research. Unless the method proves to be no different than that used on the control, one group is necessarily getting a worse treatment. Gurung and Schwartz mistakenly equate students as subjects in research, in which the treatment may or may not benefit them, and students in general. Even if we assume that discovering that a teaching method is conducive to learning will benefit future students, this does not imply that all the subjects of the research were benefited as well.

It seems plausible that dispelling the educational misconception will prove easier than will dispelling the therapeutic misconception. For one reason, many students are already aware that teaching is not the central element of their professor's career, especially in large public institutions. But even if they have this awareness, they might be under the misconception that at least in the classroom the professor's only goal is to teach well. But then, is the educational misconception even a problem? I believe it is. Considering the seriousness with which research on human subjects is conducted, and the importance placed on voluntary participation with easy opt out and informed consent, it would be a significant ethical failing if students were under the misconception that their teachers have only their learning in mind in the classroom. Of course, we are not dealing with life-and-death issues, nor even with serious consequences to students' health, either physical or mental. Yet this does not detract from the gravity of letting students continue their studies under an unnecessary misconception.

\section{FROM CLINICAL EQUIPOISE TO EDUCATIONAL EQUIPOISE}

When conducting a clinical trial, researchers often have two or more arms of the trial, meaning two or more groups of subjects that each are subject to a different intervention. One of these is usually considered a control group, a group whose intervention effects are already known. We compare the effects in the control group to the effect of the intervention in order to assess how the effects differ. Imagine a clinical trial with two arms. One arm uses a well-tried drug, known to be somewhat effective in treating the condition requiring treatment, with certain well-known side effects. The arm is meant to be the control group. The second arm uses a novel drug, which the researcher is not certain, but suspects, will be more effective in treating the condition, perhaps with fewer or less problematic side effects. This 
creates a problem for the researcher. If she believes that the novel drug is more effective in treating the condition, it would be unfair towards the control group to give them the less effective drug. After all, they have a medical condition that requires treatment and the researcher is withholding from them a drug she believes is more effective in treating the condition, Thus, the requirement for equipoise arises. It would be wrong to treat two groups of subjects differently if we believe that the different treatment results in one group receiving a benefit (harm) that the other group does not. Fairness and beneficence requires that we treat groups of subjects differently only if we are not sure that one treatment is better than the other. If we are sure that one treatment is more beneficial than another, it would be unethical to submit subjects to the less beneficial treatment when we could submit them to the treatment we are confident is more beneficial. When the researcher suspects that both treatments are somewhat effective, yet she is unsure which one is more effective, she is in a state of equipoise. If the researcher is not in a state of equipoise regarding the treatments, fairness dictates that she should treat both subject groups with the drug she believes is more effective, if she is to treat them at all.

Yet this requirement for equipoise on the part of the researcher is very demanding. Freedman (1987) dubs this type of equipoise "theoretic equipoise" and criticizes it:

Theoretical equipoise exists when, overall, the evidence on behalf of two alternative treatment regimens is exactly balanced... Theoretical equipoise is overwhelmingly fragile; that is, it is disturbed by a slight accretion of evidence favoring one arm of the trial... We may say that theoretical equipoise is balanced on a knife's edge. (p.3)

Freedman argues that while equipoise is an ethically necessary condition for clinical trials with several arms, theoretical equipoise is the wrong approach. The reason for conducting clinical trials in the first place is that there is a disagreement in the clinical community over what treatment is preferable for patients. Even if a researcher has a variety of reasons to believe that one treatment is preferable to another, the point of a clinical trial is to settle the issue conclusively. Consequently, the appropriate type of equipoise necessary is "clinical equipoise," which, according to Freedman arises when

There exists (or, in the case of a novel therapy, there may soon exist) an honest, professional disagreement among expert clinicians about the preferred treatment. A clinical trial is instituted with the aim of resolving this dispute.

At this point, a state of "clinical equipoise" exists. There is no consensus within the expert clinical community about the comparative merits of the alternatives to be tested. ( $p .4$ )

Clinical equipoise is a fundamental ethical requirement for conducting clinical trials in medicine. If the medical community is in agreement that one treatment is superior to another, it would be unethical to subject some groups of subjects to the inferior treatment.

Is there an analogical case in a teaching context? It would seem that teachers, in their role as teachers, have the obligation to teach in accordance with what is considered by the teaching community as the best teaching methods available. This need not assume that there is a one-size-fits-all teaching practice that will benefit all learners equally. Indeed, experience teaches us that some approaches work 
better with some students and worse with others. ${ }^{7}$ Instead, all that is assumed is that the teaching intervention will have either a positive or negative effect compared to the control group on average.

If a teacher-researcher intends to run a controlled experiment to test the efficacy of a certain teaching method relative to another, it seems reasonable to think that she may do so only if it was not clear which arm of the experiment is more effective. If it were clear that one arm is more effective than the other, the teacher should feel obligated to use the more effective method. It matters for whom this is not clear. Just as in the medical context, as long as the teacher-researcher is trying to convince her peers that one method is more effective than another, the relevant group is the teaching community (as analogues to the medical community in clinical equipoise). The teacher-researcher herself need not be in a state of equipoise (analogous to Freedman's theoretical equipoise). The teacher might suspect, or even be fairly certain that one method is more effective than the other. Just as in the case of clinical equipoise, proving that one intervention is more effective than the other is worth pursuing. As long as there is disagreement in the teaching community on which teaching method is more effective, the teaching community can be thought of as being in a state of educational equipoise. This would be similar to the state of clinical equipoise the medical community might be in with regard to some medical interventions.

This need not assume that we will have the same results in every educational context. A single experiment rarely tests for the entire scope of diversity of the human condition or for all possible educational contexts. Perhaps students from one culture respond better to negative feedback than students in another culture, and perhaps this is only true in classes of less than ten students and only on rainy days, although the experiment tested this only on sunny days. The experiment's findings can only ever be considered to hold conditionally (rather than necessarily true under every possible permutation of context). However, the burden of proof is on the researcher that wants to claim that a particular context is an exception. Such a researcher would need to provide some rationale for thinking that whether the weather is sunny or partly cloudy would make a difference for the outcome of the experiment. This rationale would need to be thought plausible to the members of the teaching community, who are the arbiters of whether a state of educational equipoise regarding an intervention exists. $^{8}$

Just as with the requirement for clinical equipoise, the ethical requirement for educational equipoise arises from the demand for fairness. When someone is teaching, it would be unfair to teach one group of students using methods that are inferior to the methods used for another group of students. It is only fair to use different teaching methods for different students when there is genuine educational equipoise within the teaching community. Both methods are generally considered on par, and the teacher-researcher is using different methods in order to move the teaching community out of its equipoise.

But there are several difficulties in translating the requirement for clinical equipoise to the educational setting. First, physicians often take some kind of oath, similar in spirit if not in content to the Hippocratic Oath. These can include such statements as "I will apply, for the benefit of the sick, all measures [that] are required...” from Louis Lasagna's 1964 version. Teachers, by contrast, do not swear to take on such an obligation. At least formally, there seems to be very few ethical obligations placed on teachers in a university setting that go beyond ethical requirements for people in general. Not only are university professors not bound by such oaths, they are actually thought to be entitled to academic freedom. I do not wish to deny the importance of academic freedom. However, there are many actions a 
university professor can take that would be seen as illegitimate and unacceptable while still respecting her academic freedom. Many of these have to do with how a professor treats her students. Harassment, discrimination, and abuse are all behaviors that fall outside the domain of what academic freedom allows a teacher. Teaching some students using methods that are known in the teaching community to be inferior to the methods that same teacher uses when teaching other students is simply one more illegitimate and unethical behavior. Teaching students differently when there is no equipoise about the methods needlessly harms one group of students compared to another. Such behavior is not something a teacher should be entitled to do in the name of academic freedom.

Second, the potential for harm seems much less serious in the educational context than in the clinical one. At worst, one group of students will be subject to a less than ideal learning experience. But we all know that there exist some terrible teachers out there who nonetheless continue to teach year after year and for reasons such as tenure, academic freedom, or other institutional policies or habits, and are never asked to change the way they teach. Such teachers' students are probably subjected to greater educational harm than that of a control group. Additionally, one might claim that teachers who are actively researching ways to enhance teaching effectiveness are already much more committed and better teachers than many others, and so even the control group enjoys a relatively high standard of learning. At worst, students learn a bit less than they could, so is that really a worry? But it is a worry when considering the ethics of SoTL. Just because there are worse harms to which people can be subjected in other contexts, and just because some teachers do a poor job teaching does not mean that those who seek to research their teaching need not care about the harms they inflict, minor as they might be.

Third, who the community of experts is, and when disagreements about successful treatments arise, are unclear. There are many practicing teachers in the university setting who use teaching methods that many of those in the SoTL community probably agree are inferior to others available. The standard 90-minute lecture is still employed by many teachers and they consider it the proper way to teach. If all teachers are thought to be within the teaching community, then most methods could be considered controversial and so within the domain of educational equipoise. If, however, the community to be referenced is the community of teaching scholars, encompassing only those who conduct research on teaching and learning, then the community would be much more limited and more aligned in their views. Consequently, the domain of methods to which we might claim are in a state of educational equipoise would be narrower as well.

\section{FROM CHALLENGE TO OPPORTUNITY}

How can those teachers who are thoughtful and wish to engage in SoTL meet these challenges? SoTL researchers must be aware of the potential for students to misconceive their classroom setting and work as aimed solely to advance their learning, rather than also to inform the researcher of what the effects of different interventions might be. This is by no means an invitation to refrain from conducting SoTL research. For teachers to refrain from acting as researchers as well, examining their own teaching methods and efficacy, would result in either a methodological stagnation or in an unreflective approach to developing new teaching methods.

Instead, SoTL researchers must be willing to pay the price of disillusioning students from the educational misconception. There is a price to pay because some students, once they realize that some teaching methods are not aimed solely at teaching them to the best of the teacher's ability, might wish to 
opt out. While a student might, for example, suffer my singing when under the misconception that it is meant to improve her learning, once she recognizes that I am merely testing the effects of my singing on her performance in the classroom might decide that she has no interest in being subjected to such torture. This not only reduces the subject pool for the experiment, but does so in a nonrandom manner that might invalidate the findings, as well as introduce a whole host of logistical complication when accommodating those students who wish to be excused from my singing. They will need to be assigned a different class, allowed to come in after the singing has ended, or perhaps provided noise-canceling headphones. And this is only for a minor intervention. This is no trivial matter, as there is sufficient institutional motivation for a researcher to go through the motions without really intending to rectify the misconception. Going through the motions, when the intent is not there, will most likely not bring about the needed results.

To reduce the educational misconception, researchers must make it abundantly clear-before, during, and after conducting their study - that students have indeed participated in a study. One way of making this clear prior to the study is by making sure to receive the informed consent of the potential subjects. Informed consent in this context does not merely constitute a filled-out consent form, but rather requires the conscientious effort to make sure that the consent one receives is genuine. Second, SoTL researchers must not only allow student-subjects to opt out throughout the study, but they must periodically articulate that opting out will not have any repercussions for grades. Another option is to rely on a "neutral discloser" who has no involvement in the research and as such is an uninterested party who can more reliably convey the information needed to dispel the education misconception. ${ }^{9}$ Lastly, there is need for institutional support to overcome the educational misconception. Whether it is IRBs that ask what steps were taken to overcome it or the various SoTL journals that require some evidence that attempts were made, institutional efforts to motivate researchers to take the issue seriously can be effective.

Similarly to overcoming the educational misconception, the individual SoTL researcher ought to self-regulate her behavior with respect to educational equipoise. A researcher cannot, in good conscience, teach one group of students in a way that she knows all her peers, herself included, would deem less effective than the way she is teaching another group of students. Even without any institutional enforcement, a conscientious and thoughtful teacher should avoid research that is not conducted in a state of educational equipoise.

But there can also be institutional checks in place. The SoTL community can, through its journals, conferences, and funding resources, act as a gatekeeper. If SoTL journals refuse to publish research that was conducted while not in a state of educational equipoise, as understood by the SoTL community, SoTL researchers will have no incentive to conduct such research. ${ }^{10}$ The community of SoTL researchers is the appropriate reference for the question of educational equipoise. This is a community that shares similar commitments to teaching, a community that is often in conversation with one another, a community that has shown interest in improving as teachers, using evidence in order to implement those teaching methods that appear more effective. When questions of effectiveness of a treatment are controversial among those in this community, one can legitimately claim that the issue is not settled. However, when those in the SoTL community believe that some questions of effectiveness are settled, treatments that apply teaching methods that are deemed less effective should not be used. This sets a high bar on what teaching methods are permissible in conducting a SoTL study, but it is an appropriately high bar to set. 
What this means in practice is that the SoTL community has some responsibility to regulate, through its gatekeepers, what interventions are off the table. If, by analogy, a physician suggested testing whether bloodletting is a more effective treatment for HIV than is the current standard of care, the various gatekeepers would be right to deny that physician the option of running such an experiment. This is a clear instance of an intervention that has been shown to be ineffective. Similarly, in the SoTL context, some interventions have been shown to be less effective than what is considered the current standard. If a teacher suggested testing whether a teaching technique in which students spend all their time solely introspecting in order to learn math is more effective than some of the standard teaching techniques, it would be legitimate for the SoTL gatekeepers to deny the teacher from running such an experiment.

Yet such prohibitions work well only in the most clear-cut cases. They work only when it is obvious that the proposed intervention is inferior and therefore would submit students to it would be unethical. For any less stark cases, it is ultimately up to the individual researcher to ask herself whether anyone in the SoTL community seriously entertains the possibility that the intervention she proposes is not the most effective intervention. We cannot merely rely on gatekeepers to do all the work, since reasonable people can disagree even on what the standard should be. Too lax of a control will result in no interventions being off the table. Yet too tight a control over what can be tested on part of the gatekeepers would too come dangerously close to denying academic freedom, which is so important to making progress in SoTL research. There is no a priori principle on the right level of community control, but this does not negate the fact that some level of control makes sense.

Thinking seriously about the ethical challenges that SoTL research raises gives SoTL researchers the opportunity to address these head on. While very diverse, with researchers coming from a wide range of disciplines, the SoTL community is still relatively small. Current practitioners have the opportunity to set an example and lead the way, making sure this is an area of research that will pride itself on its high ethical standards and will set the standard for academic research more generally.

Gil Hersch is a Postdoctoral Fellow in the Department of Philosophy and the Program in Philosophy, Politics, and Economics at Virginia polytechnic Institute and State University (USA).

\section{NOTES}

1. The phrase "research on students" might strike many in the SoTL community as less preferable than the phrase "research with students," since the later implies a partnership with students and treats them with due respect while the former does not. However, such sense of partnership is rarely found in random controlled trial research design, for which treating students as subjects who are intentionally kept at arm's length from the research process is an inherent part of the methodology.

2. For a critical discussion of random controlled trials see, for example, Cartwright (2007). For a critical discussion of such methods in education research, see Regehr (2010). Moreover, since controlled trials generally treat students as research subjects whose active reflection on their learning hinders the validity of the experiment by reducing the control on it, such a methodology can be viewed as antithetical to Felten's (2013) principles of good practice in SoTL.

3. Smith (2012) cites several reasons why it might be beneficial for faculty to conduct SoTL research, among them helping toward tenure and promotions, increasing one's professional recognition and standing, having the opportunity to get involved in administrative work. and becoming more effective teachers.

4. Others raise more concerns. Hutchings (2003) worries about the conditions under which it is legitimate to share students' work. Fenton and Szala-Meneok (2010) emphasize power differences 
between teacher/research and student/subject, students/subjects as a captive population, confidentiality, lost classroom time devoted to the research, and privacy in use of students' data, as ethical concerns that arise in the SoTL context. Burman and Kleinsasser (2004) go as far as providing a clear and helpful guide to approaching SoTL research ethically.

5. Appelbaum et al. tested it only among chronic schizophrenics and people with borderline personality disorders, but later studies found the therapeutic misconception to be prevalent among a wide variety of medical patients-subjects (Dresser, 2002).

6. Leentjens and Levenson (2013) also use the term "educational misconception," but they do so in reference to the misconception that participating in psychological experiments is supposed to provide an educational benefit to the students participating in them.

7. I thank an anonymous reviewer for raising this point.

8. I thank Gary Poole for raising this point.

9. See (Dresser, 2002) for this and other proposals in the therapeutic misconception context.

10. Some disciplines have such self-regulation on research methods they deem problematic. An example would be experimental economics' ban on explicit deception (Hersch, 2015).

\section{REFERENCES}

American Association of University Professors \& Association of American Colleges (1970). 1940 Statement of Principles on Academic Freedom and Tenure, with 1970 Interpretive Comments. Retrieved from https://www.aaup.org/report/1940-statement-principles-academic-freedom-and-tenure

Appelbaum, P. S., Roth, L.H., \& Lidz. C. (1982). The therapeutic misconception: Informed consent in psychiatric research. International Journal of Law and Psychiatry, 5(3-4), 319-329. https://doi.org/10.1016/01602527(82)90026-7

Burman, M. E. \& Kleinsasser, A. (2004). Ethical guidelines for use of student work: Moving from teaching's invisibility to inquiry's visibility in the Scholarship of Teaching and Learning. Journal of General Education, 53(1), 59-79. https://doi.org/10.1353/jge.2004.0018

Cartwright, N. (2007). Are RCTs the gold standard? BioSocieties, 2(1), 11-20. https://doi.org/10.1017/S1745855207005029

Dresser, R. (2002). The ubiquity and utility of the therapeutic misconception. Social Philosophy \& Policy, 19(2), 271294. https://doi.org/10.1017/S0265052502192119

Felten, P. (2013). Principles of good SoTL practice. Teaching \& Learning Inquiry, 1(1), 121-125. https://doi.org/10.20343/teachlearninqu.1.1.121

Fenton, N. E. \& Szala-Meneok, K., (2010). Research on Teaching and Learning Guidebook. Hamilton, ON: McMaster University.

Freedman, B. (1987). Equipoise and the ethics of clinical research. New England Journal of Medicine, 317(3), 3-16. http://dx.doi.org/10.1056/NEJM198707163170304

Gurung, R. A. R., \& Schwartz, B. M. (2009). Optimizing Teaching and Learning. Malden, MA: Wiley-Blackwell. https://onlinelibrary.wiley.com/doi/book/10.1002/9781444305883

Hersch, G. (2015). Experimental economics' inconsistent ban on deception. Studies in History and Philosophy of Science Part A, 52, 13-19. https://doi.org/10.1016/j.shpsa.2015.04.005

Hutchings, P. (2003). Competing goods: Ethical issues in the Scholarship of Teaching and Learning. Change, 35(5), 26-33. https://doi.org/10.1080/00091380309604116

Leentjens, A. F. G., \& Levenson, J. L. (2013). Ethical issues concerning the recruitment of university students as research subjects. Journal of Psychosomatic Research, 75(4), 394-398. https://doi.org/10.1016/j.jpsychores.2013.03.007

Martin, R. C. (2013). Navigating the IRB: The ethics of SoTL. New Directions for Teaching and Learning, 2013(136), 59-71. https://doi.org/10.1002/tl.20076

McKinney, K. (2007). Enhancing Learning Through the Scholarship of Teaching and Learning. Bolton, MA: Anker Publishing Company.

Miller, F. G. \& Brody, H. (2003). A critique of clinical equipoise: Therapeutic misconception in the ethics of clinical trials. Hastings Center Report, 33(3). 19-28. https://doi.org/10.2307/3528434

Pritchard, I. A. (2002). Travelers and trolls: Practitioner research and institutional review boards. Educational Researcher, 31(3), 3-13. 
Regehr, G. (2010). It's NOT rocket science: Rethinking our metaphors for research in health professions education. Medical Education, 44(1), 31-39. https://doi.org/10.1111/j.1365-2923.2009.03418.x

Smith, R. (2008). Moving toward the Scholarship of Teaching and Learning: The classroom can be a lab, too! Teaching of Psychology, 35(4), 262-266. https://doi.org/10.1080/00986280802418711

Smith, R. A. (2012). Benefits of using SoTL in picking and choosing pedagogy. In B.M. Schwartz \& R. A. R. Gurung (Eds.), Evidence-based Teaching for Higher Education (pp. 7-22). Washington, DC: American Psychological Association.

Swenson, E. \& McCarthy, M. (2012). Ethically conducting the Scholarship of Teaching and Learning research. In R. E. Landrum \& M. A. McCarthy (Eds.), Teaching Ethically: Challenges and Opportunities (pp. 21-29). Washington, DC: American psychological Association.

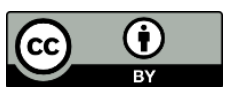

Copyright for the content of articles published in Teaching \& Learning Inquiry resides with the authors, and copyright for the publication layout resides with the journal. These copyright holders have agreed that this article should be available on open access under a Creative Commons Attribution License 4.0 International (https://creativecommons.org/licenses/by/4.0). The only constraint on reproduction and distribution, and the only role for copyright in this domain, should be to give authors control over the integrity of their work and the right to be properly acknowledged and cited, and to cite Teaching \& Learning Inquiry as the original place of publication. Readers are free to share these materials — as long as appropriate credit is given, a link to the license is provided, and any changes are indicated. 